\title{
From "sigma test" to customized training
}

\section{Salvatore Buzzelli}

\author{
ABSTRACT \\ This article illustrates how you can assign a metabolic exercise to a tennis player, after \\ having performed the "Sigma Test" and having acquired the subjective parameters.
}

Key words: Sigma Test, Tennis, Assessment Test, Tennis Training, Metabolic Training, Physical form, Attention Energy Cost

Received: 10 April 2021

Acepted: 30 May 2021

Corresponding author: Email: salvatorebuzzelli1@gmail.com

\section{INTRODUCTION}

As can be seen from all the studies performed on the tennis performance model, the tennis player must have a good degree of organic and local muscular resistance, bearing in mind not to exacerbate the methods and training times as if we were facing a marathon runner.

In fact, much of the tennis player's stamina derives from his strong ability to mentally resist effort. From this point of view, working with the "SensoBuzz" app becomes decisive, as the aspect of central fatigue, therefore nervous, is very stressed (Buzzelli, 2007) (Smith, 2016).

In the "Coordinabolic Method" (Buzzelli, 2008), we start from the evaluation of the organic abilities under attentive aegis, through the "Sigma Test" (Buzzelli, 2008), which will indicate the parameters on which the subsequent specific training will be based.

In fact, when the "Sigma Test" is completed, we will have three fundamental parameters that will help us manage the individualized dosage: the meters traveled by moving back and forth from the base to the target, with technical running (considering that the base-target distance is set at $5.50 \mathrm{~m}$ ), the emission time of the signals that the student has performed in the last phase of the test (TC or Critical Time) and the number of signals performed (Cycles).

Based on these three parameters, the best choice can be made in relation to what you want the athlete to achieve, in terms of "Capacity" and "Power" of the individual energy systems (Weinieck, 2009).

To better understand these concepts, we use a synoptic framework, summarized in the following table.

Tables 1 and 2: General indications for dosing the load according to the metabolic goals and critical time (Tc) obtained by the athlete in the Sigma Test, and the relative recommended spaces between the base and the target.

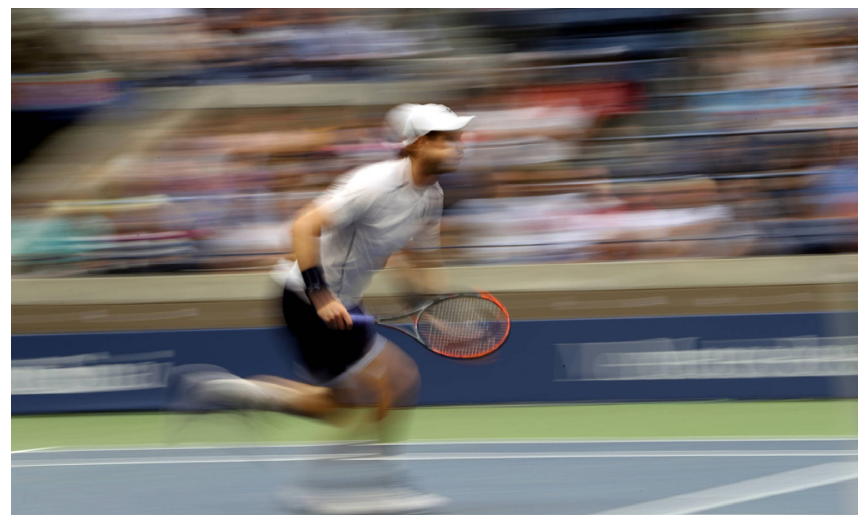

Table 1

\begin{tabular}{llllllllllll}
\hline CAPACITY & (percentage \pm of time compared to TC) \\
\hline $\begin{array}{l}\text { Meters } \\
\text { (base- } \\
\text { target) }\end{array}$ & 5,50 & 5,00 & 4,50 & 4,00 & 3,50 & 3,00 & 2,50 & 2,00 & 1,50 & 1,00 \\
$\begin{array}{l}\text { Capacity } \\
\text { Anaerobic }\end{array}$ & $-5 \%$ & $-10 \%$ & $-15 \%$ & $-22 \%$ & $-25 \%$ & $-33 \%$ & $-35 \%$ & $-50 \%$ & $-55 \%$ & $-70 \%$ \\
Alactacid & & & & & $X$ & $X$ & $X$ & $X$ & $X$ & $X$ \\
Anaerobic & & & $X$ & $X$ & $X$ & $X$ & & & & \\
Lactacid & & & $X$ & & & & & & & \\
Aerobic & $+8 \%$ & $+3 \%$ & & & & & & & & & \\
\hline
\end{tabular}

Table 2

\begin{tabular}{|c|c|c|c|c|c|c|c|c|c|c|}
\hline $\begin{array}{l}\text { Metri (base- } \\
\text { target) }\end{array}$ & 5,50 & 5,00 & 4,50 & 4,00 & 3,50 & 3,00 & 2,50 & 2,00 & 1,50 & 1,00 \\
\hline Power & $-15 \%$ & $-20 \%$ & $-32 \%$ & $-34 \%$ & $-36 \%$ & $-42 \%$ & $-47 \%$ & $-56 \%$ & $-60 \%$ & $-75 \%$ \\
\hline $\begin{array}{l}\text { Anaerobic } \\
\text { Alactacid }\end{array}$ & & & & & & & $x$ & $x$ & & \\
\hline $\begin{array}{l}\text { Anaerobic } \\
\text { Lactacid }\end{array}$ & & & & & $x$ & $x$ & & & & \\
\hline Aerobic & TC & $-8 \%$ & & & & & & & & \\
\hline
\end{tabular}


The recommended training load will be that indicated in the following table.

Table 3

Example of load dosage according to the metabolic quality to be stimulated.

\begin{tabular}{lcc}
\hline \multicolumn{1}{c}{$\begin{array}{c}\text { Trained Metabolic } \\
\text { Quality }\end{array}$} & $\begin{array}{c}\text { Sets, Series and } \\
\text { Repetitions }\end{array}$ & $\begin{array}{c}\text { Break between series } \\
\text { and between sets }\end{array}$ \\
\hline $\begin{array}{l}\text { Quickness } \\
\text { Alactacid Anerobic } \\
\text { Capacity }\end{array}$ & $3 \times 10 \times 8-10$ & $15^{\prime \prime}-1^{\prime} 30^{\prime \prime}$ \\
$\begin{array}{l}\text { Alactacid Anaerobic } \\
\text { Power }\end{array}$ & $2 \times 10 \times 7-9$ & $30^{\prime \prime}-2^{\prime} 30^{\prime \prime}$ \\
$\begin{array}{l}\text { Lactacid Anaerobic } \\
\text { Capacity }\end{array}$ & $2 \times 18 \times 15$ & $45^{\prime \prime}-3^{\prime}$ \\
$\begin{array}{l}\text { Lactacid Anaerobic } \\
\text { Power }\end{array}$ & $12 \times 12$ & $1^{\prime} 30^{\prime \prime}-5^{\prime}$ \\
Aerobic Capacity & $6 \times \quad$ (Cicli / 2) & $\begin{array}{r}2^{\prime} 30^{\prime \prime} \text { Active Pause } \\
\text { Aerobic Power }\end{array}$ \\
\hline
\end{tabular}

\section{TOOLS AND METHODS}

To carry out this exercise, starting from 2007 (S. Buzzelli, 2007), a special tool called initially "SensoTouch" and then definitively "SensoBuzz", was used but currently it is possible to use a smartphone application, also called "SensoBuzz" (S. Buzzelli, 2019), which emits visual and acoustic signals in a random mode with a pre-established time scan. The exercise is performed in a space as illustrated in Figure 1.

\section{EXECUTIVE PROTOCOL}

The following figure illustrates the recommended arrangement of the targets for the execution of the metabolic work described above.

You can use three visual and two sound signals or even more than 5 signals or other types of signal or variants to increase the degree of difficulty.

Issue times, travel distances, purposes and workloads are described in the previous tables (Tab. 1,2,3).

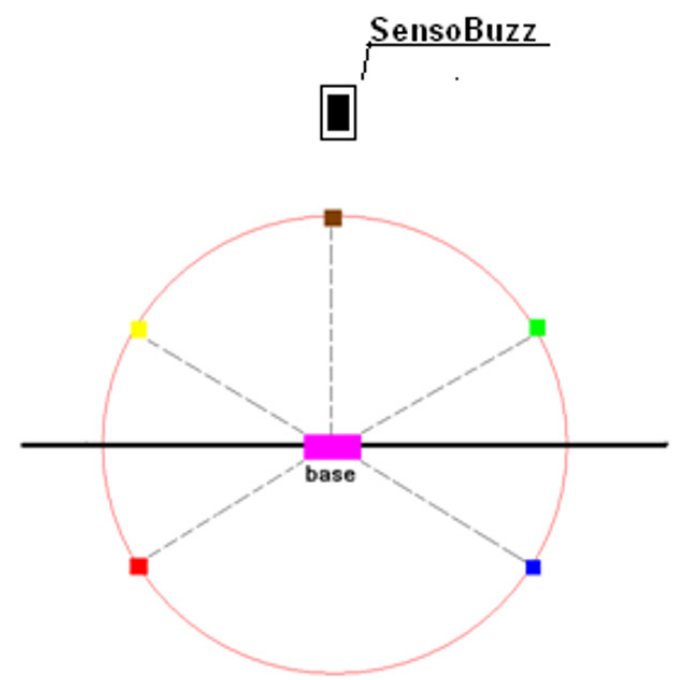

Figure 1.

\section{REFERENCES}

Buzzelli S., SensoTouch Buzzelli System, Pubblicazioni, salvatorebuzzelli.it, 2007

Buzzelli S., Sigma Test, Pubblicazioni, salvatorebuzzelli.it, 2008

Buzzelli S., Metodo Coordinabolico, Pubblicazioni, salvatorebuzzelli.it, 2008

Buzzelli S., SensoBuzz, C.E.Youcanprint - 2013

Buzzelli S., Costo energetico dell'attenzione, Ricerca Scientifica, salvatorebuzzelli.it, 2014

Buzzelli S., Mazzilli M., TENNIS. La nuova scienza della Preparazione Fisica con il rivoluzionario Metodo Coordinabolico. Giacomo Catalani Editore, 2019

Buzzelli S., Manuale fondamentale di Preparazione Fisica per il Tennis, Giacomo Catalani Editore, 2020

Smith et al, Mental fatigue impairs soccer-specific decision making skill, (2016) Journal of Sports Sciences

Weinieck J., L’Allenamento Ottimale, Calzetti Mariucci, 2009 transform, and build upon the material for any purpose, even commercially under the following terms:

Attribution: You must give appropriate credit, provide a link to the license, and indicate if changes were made. You may do so in any reasonable manner, but not in any way that suggests the licensor endorses you or your use. 